\title{
PRESUPUESTOS PROCESALES Y SU DECAIMIENTO EN LOS JUICIOS PERSONALÍSIMOS. LA CAPACIDAD PROCESAL EN EL CASO "QUEZADA ARIAS CON FARÍAS LAURI"
}

\section{EDUARDO GANDULFO R. ${ }^{*}$}

\section{INTRODUCCIÓN}

Constituye un absoluto lugar común en las exposiciones y comentarios sobre los presupuestos procesales, principiar señalando que $\mathrm{O}$. von Bülow es el creador de esta idea en oposición a la de excepciones procesales y que los concibió como "condiciones para la constitución de la relación jurídica procesal”, de tal manera que sin ellos no habría proceso ${ }^{1}$. Pero, igualmente, constituye un lugar común hacer la advertencia de que, sin embargo lo expuesto, "ninguna de sus aportaciones logró sobrevivir en su prístina pureza. La tesis de la relación encontró desenvolvimientos contradictorios y fue atacada finalmente por Goldschmidt, creador de la tesis del proceso como situación. Los presupuestos han sido explicados de tan diversos modos, que actualmente no tienen la función que les asignara su autor. Y las excepciones continúan siendo tratadas como si nada definitivo hubiera sido argumentado en su contra" ${ }^{2}$. Pero así como más de alguna vez, por los problemas citados, se ha pretendido deshacerse de dicha idea, así también vemos que ella brota una y otra vez en la realidad comprensiva del Derecho Procesal.

El caso 'Quezada Arias con Farías Lauri' resuelto por la Corte de Apelaciones de Valparaíso, de la pluma del juez Arancibia Pinto 3 , apunta precisamente en dicha dirección, y se tiende a erigir en una de las más importantes sentencias, técnicamente hablando, de la historia del Derecho

Abogado, Pontificia Universidad Católica de Valparaíso, Postgraduado como Especialista en Argumentación Jurídica por la Universidad de Alicante (España). Profesor de la Universidad Nacional Andrés Bello. Agradezco a Alejandro Romero, Francesco Carretta y Rafael San Martín por sus lecturas y críticas del presente texto. Correo electrónico: ednega@gmail.com

1 Von Bülow, O. (1868). La Teoría de las Excepciones Procesales y los Presupuestos Procesales, EJEA, trad. M. Rosas, B. Aires, pp. 4 y ss. Disponible en http://forodelderecho.blogcindario.com/2011/05/01622-la-teoria-de-las-excepciones-y-los-presupuestos-procesales-oskarvon-bulow.html

2 Briseño Sierra, H. (1966). "Excepciones Procesales", en Revista de la Facultad de Derecho de México, No 63-64, pp. 770. Sobre la evolución alemana del tema, Pérez Ragone, A. (2010). “¿Presupuestos Procesales? Admisibilidad y Fundabilidad en la Dogmática Procesal Civil Alemana: Revisión Contemporánea”, en Teoria do Processo, Vol. 2, pp. 21 a 44.

3 Corte de Apelaciones de Valparaíso. Sentencia de 18 de agosto de 2008. También concurrieron con sus votos los jueces G. Morales Herrera y C. Müller. 
procesal patrio. Agréguese a la complejidad del caso, el que la materia versó sobre una situación especial: se trató de un decaimiento del presupuesto y no de una falta $a b$ initio; asimismo, el juicio era un proceso de carácter personalísimo (en donde no cabe la sucesión procesal), sin olvidar que el proceso de divorcio se trata de uno de la clase de los constitutivos. En el conflicto que se planteó, chocaron los presupuestos procesales versus la suma preclusión y/o el desasimiento judicial. A todo lo anterior, finalmente debe sumársele la vía para hacer valer la sentencia.

La causa se trató de lo siguiente: En un matrimonio, el marido demandó a su cónyuge de divorcio unilateral. Dándose todos los presupuestos procesales y los requisitos de fondo, se decretó el divorcio por sentencia definitiva del juez de familia de Viña del Mar, el 30 de mayo de 2007. Dado que estaba sometida al primer régimen del divorcio chileno, la sentencia debió consultarse ante la Corte de Apelaciones de Valparaíso, cosa que ocurrió aprobándose la sentencia, el 5 de noviembre de 2007. En el tiempo intermedio murió el demandante, no siendo avisado el evento por el abogado del actor, continuándose así el proceso. Luego, el 6 de diciembre de 2007 se dictó el "cúmplase" de la sentencia en el Tribunal de Familia, habiendo así precluido todos los medios de impugnación de la sentencia prima facie. Estando pendiente el proceso para cumplirse la sentencia, tomó conocimiento la parte demandada y presentó un incidente de nulidad del proceso basado en la muerte del actor, como óbice al divorcio, por haber operado primero una causa de disolución del matrimonio, y en razón de los perjuicios que le acarrearía a su parte la sentencia al afectarle en sus derechos hereditarios y el derecho a percibir el montepío producto de su condición de viuda.

Desde el punto de vista del marco teórico, para la explicación del caso desarrollaré algunas teorías de los presupuestos procesales de manera analítica, y propondré una visión alternativa de acuero a ciertos materiales críticos. Luego esbozaré ciertos elementos de la categorización de los procesos personalísimos, en relación con la sucesión procesal. Posteriormente, revisaré el decaimiento de los presupuestos. Finalmente, examinaremos la vía de hacer valer la consecuencia de su falta, en relación con la teoría de la nulidad procesal. Todo lo cual se hará dentro del marco de extensión posible de un comentario de sentencia.

\section{1) EL PROBLEMA Y LA PUNTA DE SOLUCIÓN}

En verdad, el caso muestra toda la importancia e influencia de la teoría jurídica tanto de los autores como de la propia judicatura, en la toma de decisiones de los tribunales en el momento de la aplicación del Derecho. En efecto, el fallo del caso 'Quezada Arias con Farías Lauri', se basa en un antecedente técnico-teórico crucial: el informe de la fiscal judicial 
Nash. En el mencionado informe, la fiscal se apoya en dos tipos de fuentes relevantes: 1) Las teorías procesales de los presupuestos que sustentan los profesores Pereira Anabalón y Romero Seguel, y 2) el famoso caso 'Novoa Chevesich con SIT, resuelto por la Corte de Apelaciones de Santiago, pero referido a la ausencia ab initio de los presupuestos.

La relevancia de esta toma de posición teórica, radica en que la propuesta del recurrente de enfrentar el problema desde los puntos de vista de fondo y temporal -es decir, que el fallecimiento ocurrió previo a quedar firme la sentencia, y que, por tanto, operó de pleno Derecho otra causal de disolución del matrimonio, que desplazaría a la sentencia jurisdiccional- tiene un problema técnico básico: plantea una discusión de fondo frente a un problema estrictamente formal o procesal. Es cierto que de fondo pueden ocurrir múltiples situaciones, y la discusión puede prolongarse eternamente respecto a quién tiene qué derecho en un caso particular. Sin embargo, por un asunto de seguridad y certeza jurídica, la estabilidad de la condiciones de vida deben asegurarse mediante la pérdida de las facultades y derechos procesales; aunque se tenga razón sobre el fondo. Y, en tal sentido, es la judicatura la que tendrá la última palabra sobre un caso particular, desde el punto de vista de la operatividad del sistema. En suma, lo que digo aplicado al caso es que, primero que todo, la solución propuesta por el incidentista de nulidad, estaba bloqueada por la preclusión procesal sea la refleja o pro iudicato que afecta al órgano jurisdiccional ${ }^{4}$. Como dio cuenta el juez de familia, este no podría cambiar la resolución en razón de haber operado el desasimiento del tribunal (modalidad de preclusión pro iudicato). De tal manera, la relevancia de la solución teórica de la fiscal judicial Nash y del juez Arancibia saltan a la vista con claridad.

Se requería una figura jurídica que tuviese la potencia suficiente para destrabar el obstáculo de la preclusión. Ahora bien, por lo que sabemos, son muy específicos y pocos los instrumentos legales que puedan lograr aquello, de tal manera que debió recurrirse a uno que socavara desde su base a la preclusión, y ese, al parecer, no podía ser otro que el de los presupuestos del proceso.

\section{2) SOLUCIÓN DEL FALLO Y SU UBICACIÓN TEÓRICA}

El problema siguiente no deja de ser menor. Sobre la base de la intuición de los presupuestos procesales, se erige toda una gama de construcciones teóricas de muy diferente espectro, tanto a nivel de la comprensión

Sobre ambas variantes Gandulfo, E. (2009). "Sobre Preclusiones Procesales en el Derecho Chileno en Tiempo de Reformas”, en Ius et Praxis, Vol. 15, No 1, pp. 137 y 138. 
conceptual como del alcance de la figura, que relativizan la elección de la sentencia. La variedad teórica podríamos resumirla en las siguientes tesis:

(a) Los presupuestos procesales son de la validez del proceso completo y sus actos. Esta tesis distingue entre los presupuestos de "existencia" y de "validez" del mismo, según su posibilidad de saneamiento.

(b) Los presupuestos son de admisibilidad del proceso y de todos sus actos.

(c) Los presupuestos son de admisibilidad de la sentencia de fondo.

d) Los presupuestos son de la acción y así del proceso ${ }^{5}$.

\section{(2.1) VARIEDADES TEÓRICAS}

La gran variedad de concepciones por supuesto que tienen consecuencias en las vías de hacer valer el problema. La decisión de la Corte de Apelaciones de Valparaíso y la de la fiscal Nash se inclinaron por la primera solución (a). La razón, a mi juicio, está en que para los efectos de este tipo de proceso tan particular, era mucho más sencillo y hacía más razón la tesis de Von Bülow, seguida por H. Pereira (que la de Goldschmidt, seguida por A. Romero, bastante más compleja y menos intuitiva). En efecto, para vencer la suma preclusión (y mal llamada autoridad de cosa juzgada formal ${ }^{6}$ ), la concepción de Von Bülow es clara al señalar que sin presupuestos no hay condiciones para formar un proceso, y si ello es así, entonces solo tenemos una apariencia de proceso y, conjuntamente, una apariencia de suma preclusión o cosa juzgada aparente. Así es posible remover de manera coherente -con las hipótesis iniciales o superiores de nuestra área del Derecho- el obstáculo procesal, sin inventar una excepción ad hoc, que apele consideraciones de justicia superior, extrasistema, (como sí se hizo en 'Novoa Chevesich con SII mediante el recurso al Derecho natural ${ }^{7}$ ). En nuestro caso, el movimiento es mecánicamente casi impecable (sin perjuicio de algunos problemas teóricos).

Observemos que la Corte de Apelaciones de Valparaíso dictamina como base que: "si bien el Tribunal ha dictado el cúmplase, y sin perjuicio de que la subinscripción no se había efectuado, en realidad no ha opera-

5 Couture si bien los refiere a la acción termina afectando a la existencia del proceso, por lo que por extensión también termina como presupuesto de existencia del proceso: "Podemos definir, pues, este primer grupo de presupuestos procesales, como aquellos cuya ausencia obsta al andamiento de una acción y al nacimiento de un proceso", por lo que los califica de "presupuestos procesales stricto sensu". Couture, E. (1958). Fundamentos de Derecho Procesal Civil, $3^{a}$ edic., Buenos Aires: Depalma, p. 104 y 105.

Gandulfo (2009) 150.

Corte de Apelaciones de Santiago, sentencia de 24 de mayo de 2000, rol 2540-1999 (al que están acumuladas las apelaciones $\mathrm{N}^{\circ} 4438-1999$ y 7036-1999), y a la cual concurrieron con sus votos R. Camposano y S. Araneda Briones. 
do el referido desasimiento del Tribunal, por cuanto en la especie al haber muerto uno de los contrayentes durante la substanciación del proceso, ha desaparecido uno de los presupuestos de existencia del proceso, cual es la existencia física o legal de las partes" (considerando $7^{\circ}$ ). Como puede apreciarse, se toma posición por el criterio de existencia del proceso poniéndolo en relación con la preclusión del tribunal en su variante del desasimiento, para, precisamente, obliterar dicho desasimiento. Tómese en cuenta que se trata de un proceso llamado "constitutivo", en que la sentencia constituye el nuevo estado o situación, a diferencia de los de condena que requieren de la ejecución postrera. Complementando la misma idea de socavamiento de las bases del desasimiento y la preclusión, se afirma por la sentencia: "Que, en concreto, habiendo continuado el proceso con posterioridad a la muerte de una de las partes, ello ha tenido una naturaleza aparente, carente de un requisito esencial, de manera que todo lo obrado con posterioridad al 7 de julio del 2007, carece de valor y así debe ser declarado" (consid. 9o).

\section{(2.2) Alternativas teóricas}

Por cierto, la teoría invocada por el fallo no forma parte de la opinio iuris communis; en otros términos, no es la teoría válida actualmente en el ámbito procesal. Veamos un breve listado de algunas alternativas.

(a) La primera señala que los presupuestos son elementos constitutivos de la relación procesal, es decir, son de la existencia del proceso; y su falta impediría el surgimiento del proceso ${ }^{8}$. Así, cuando estamos frente a un no juez, lo que en realidad sucede allí es que no podemos identificar los elementos conceptuales mínimos para estimar que haya un proceso en la forma que lo entendemos ${ }^{9}$. Dependiendo de las consecuencias jurídicas sobre el proceso, se distingue entre los tipos de presupuestos: unos que afectan la validez del mismo y otros que afectan la existencia de la relación procesal $(\mathrm{H} \text {. Pereira })^{10}$. Dependiendo de lo radical de la falta de validación del proceso y su posible saneamiento o no mediante la autoridad de cosa juzgada.

(b) Las posturas que sustentan el carácter de admisibilidad/inadmisibilidad relativo a los presupuestos procesales, se ordenan desde un aspecto crítico a la anterior postura. Se apoyan en dos razones: primero, que el descubrimiento de que no concurren los presupuestos en un proceso, no conduce a considerarlo como no sucedido (o no

Von BüLOw (1858) 5-6.

Corte Suprema, caso 'Sociedad Sánchez y Sánchez Limitada con SII', sentencia de 4 de junio de 2008, causa rol 2849-2007, redactada por el juez Pierry.

10 Pereira, H. (2004). La Cosa Juzgada en el Proceso Civil, Santiago: LexisNexis, pp. 125 a 131. 
realizados los trámites) en la realidad, sino que más bien se impide el desenvolvimiento postrero del proceso, mediante una sentencia interlocutoria; y en segundo, porque los propios presupuestos son objeto de examen y resolución en el proceso y, por tanto, presuponen su existencia (de lo que se desprende que no pueden ser al mismo tiempo presupuestos de dicha existencia) ${ }^{11}$; es decir, llegaríamos a una paradoja de no seguir esta línea argumentativa. Por lo tanto, no se les puede concebir como presupuestos para la existencia del proceso ${ }^{12}$. Pero hasta allí llegan las coincidencias.

(c) Un presupuesto procesal se trata más bien de circunstancias formales que deben estar presentes en el proceso, para que se pueda dictar una sentencia sobre el fondo de la cuestión jurídica planteada ${ }^{13}$. En suma, se trata de una condición de la sola admisibilidad del dictado de la resolución de mérito ${ }^{14}$ o la "perseguibilidad" del hecho punible ${ }^{15}$.

En consecuencia, dado que son presupuestos de admisibilidad de la sentencia de fondo, nos dice Romero, su falta provoca el dictado de una sentencia meramente procesal, que absuelve solo de la instancia o del proceso, sin pronunciarse del fondo debatido. Agrega que esta resolución es una sentencia definitiva atípica dentro de las que prescribe el art. 158 CPC, y que habría casos similares en los arts. 477 y 690 $\mathrm{CPC}^{16}$. Si se admitiese la concepción anulatoria del proceso se descalabraría el sistema procesal, pues se convertiría al incidente de nulidad en una especie de acción de nulidad independiente pero accesoria al proceso, siendo que la acción de nulidad de un juicio mediante otro proceso con dicho objeto principal, fue derogada por la ley del primero de marzo de 1837. Actualmente queda en nuestro sistema, solo la opción de la acción de revisión del art. $810 \mathrm{CPC}$, que no incluye la falta de presupuestos procesales y el caso excepcionalísimo del art. 80 CPC. Dicha solución es consistente solo con la presente teoría.

11 Rosenberg, L. (1955). Tratado de Derecho Procesal Civil, t. II, Buenos Aires: EJEA, p. 47.

12 Schmidt, Eb. (1957). Los Fundamentos Teóricos y Constitucionales del Derecho Procesal Penal, Buenos Aires: Editorial Bibliográfica Argentina, p. 80.

13 Romero, A. (2001). "El Control de Oficio de los Presupuestos Procesales y la Cosa Juzgada Aparente. La Capacidad Procesal", en RCHD, Vol. 28, p. 782.

14 Romero, A. (2006). Curso de Derecho Procesal, t. I, Santiago: Editorial Jurídica de Chile, p. 27; Pastor, D. (2001). Acerca de Presupuestos e Impedimentos Procesales y sus Tendencias Actuales, en Nuevas Formulaciones en las Ciencias Penales, Buenos Aires: Lernes, p. 796. Goldschmidt señala que los "presupuestos procesales no lo son, en realidad, del proceso; son, simplemente, presupuestos, requisitos previos de la sentencia de fondo, sobre los que resuelve el proceso" Goldschmidt, J. (1936). Derecho Procesal Civil, Barcelona: Labor, p. 8. No obstante, Schmidt objeta que Goldschmidt tiene un concepto más amplio que el mero presupuesto inmediato de la sentencia de fondo, llegando a considerarlos también como presupuestos de la acción y de la admisibilidad de la acusación. Sснмidt (1957) 79-80.

15 Fairén, V. (1992). Teoría General del Derecho Procesal, México: UNAM, p. 340.

16 Romero, A. (2004). "La Falta de Jurisdicción y su Denuncia en el Proceso: las Excepciones Procesales y Materiales”, en RCHD, Vol. 31, pp. 191 y 192. 
(d) La tesis del presupuesto entendido como de admisibilidad del proceso completo, señala que aquel debe comprenderse como algo más que "presupuestos sentenciales" para el mero dictado de una sentencia de fondo cualquiera sea esta, siendo insuficiente que se diga que no evitan la concreta realización del proceso. Como bien dice Rosenberg, se refieren o abarcan la totalidad del proceso particular dirigido a una sentencia de fondo ${ }^{17}$. Por ende, con los presupuestos procesales sensu strictus, se abarca también, como consecuencia, la actuación propia de los presupuestos sentenciales, pero realizan algo más. De esta manera, si se invoca la jurisdicción frente a una persona ficticia o inexistente, para obtener ciertas ventajas en el intertanto del dictado de la sentencia, como p. ej., derechos permanentes de un interlocutorio, estos no tendrán valor alguno.

En suma, la afectación sobre el proceso actúa a título de admisibilidad del proceso concreto de que se trate, por lo que ese algo más afecta no solo a la eventual sentencia de fondo, sino que a la admisibilidad de la demanda, del debate oral y las cautelares de todo tipo que se den, incluso hasta la admisibilidad de la propia cosa juzgada ${ }^{18}$. De esa forma tutela los efectos de los actos intermedios y la apariencia de autoridad de cosa juzgada.

A mi juicio, lo que sea un presupuesto procesal tiene que ver inextricablemente con la idea de "proceso"19. Si miramos el proceso como una serie concatenada de cosas, vemos que tiene una composición compleja de: $a$ ) actos procesales particulares y $b$ ) resoluciones procesales singulares. La complejidad está en que los primeros pertenecen al mundo del ser y no tienen una consideración deóntica, mientras que los segundos -sabemos con Kelsen- pertenecen al mundo normativo o del deber ser, y están sometidas al criterio de validez o invalidez, es decir, de la fuerza obligatoria de algo, que constituye, además, la manera especial de existir de las normas. Así que cuando privamos de validez a una norma, la excluimos del mundo deóntico. Pero con los actos y los hechos no ocurre lo mismo, ya que no se anula un hecho o un acto, pues estos dejan su marca en el

17 Rosenberg (1955) 45.

18 Rosenberg, señala que "los presupuestos procesales, como condiciones de admisibilidad de todo el proceso, lo son tanto de la demanda (que se rechazará como improcedente en caso de su falta), de la sentencia sobre la causa (que no puede dictarse), como también del debate oral y de la recepción de la prueba, que no deben tener lugar, en tanto se establezca la falta de presupuesto procesal y quedarán sin objeto cuando se produzca tal falta en el transcurso del procedimiento". ROSENBERG (1955) 45-46.

19 En tal sentido, la intuición de Von Bülow es inteligente, al relacionarla con su propia concepción de lo que sea el proceso, según veremos; aunque puede que sus consecuencias no sean del todo correctas (como en parte dan cuenta Goldschmidt (1936) 8 y RosenberG (1955) 47. 
mundo físico y están sometidos a otros criterios, como, p. ej., de existencia o inexistencia. En consecuencia, una demanda no es inválida o válida, porque no obliga o vincula por sí misma a nadie; son las normas las que establecen consecuencias deónticas de obligar al juez a tramitar y disponen una serie de consecuencias jurídicas para las partes. La demanda es admisible o inadmisible, pero como acto ya se radicó en el mundo de los hechos ${ }^{20}$. Lo que produce la confusión es que tanto los actos procesales como las normas comparten el que ambos puedan tener ciertos vicios jurídicos, en consideración a su contrastación con las normas superiores que los regulan. La falta de un presupuesto procesal, desde esta perspectiva, sería un vicio que afectaría al proceso, como situación compleja, provocando a la vez la inadmisibilidad e invalidez del mismo.

Esta manera de mirar el proceso, si bien tiene ciertos méritos no despreciables, me parece altamente insatisfactoria desde el punto de vista metodológico, pues implica una mirada en bruto del aquel, y de lo que estamos hablando es de un problema que se da a nivel interpretativo o teórico de la comprensión del proceso como una entidad colectiva diversa de cada uno de sus componentes singulares, que, por tanto, no se resuelve con la mera observación en bruto de lo que son los procesos. Y este problema de enfoque creo que termina permeando este doble régimen a que se ha de atribuir bajo esta concepción, incurriéndose así en la falacia de la composición, al traspasar el régimen propio de los componentes al colectivo ${ }^{21}$.

En verdad, la solución es metodológicamente más pesada aunque más sencilla desde el punto vista teórico. Lo primero que hay que afirmar es la diferencia entre clase y miembro, como ya lo habíamos esbozado. El proceso constituye una entidad colectiva, diferente de los miembros singulares que agrupa, como, p. ej., los actos procesales singulares del tipo demanda de Juan, traslado del juez Morgado, etc. Los presupuestos procesales se predican respecto del ente colectivo. Segundo, si observamos el proceso bajo la perspectiva de la relación jurídica, vemos que los sujetos no están conectados al azar, sino que están preordenados con base en: normas jurídicas generales de tipo procedimental que se aplican al caso particular (a actos y resoluciones individuales) y otras normas singulares que son las resoluciones que van ordenando el proceso. Precisamente, al faltar los presupuestos procesales en el caso particular se afecta la validez o la fuerza obligatoria de las normas generales, pero no desde un contexto general,

20 Esta explicación ya la he sostenido en Gandulfo (2009) 188-189.

21 Además, esto pondría de manifiesto que esta visión se encontraría afecta a la falacia de la composición. Esta falacia consiste en concluir (colectivamente) que una clase posee una determinada característica o propiedad porque cada miembro de la clase tendría. SALMON, W. (1965). Lógica, México: UTEHA, p. 60; CopI, I. (1994). Introducción a la Lógica, Buenos Aires: EUDEBA, pp. 109 a 111; y Gómez, A. / Buera, O.M. (1984). Análisis del Lenguaje Jurídico, Buenos Aires: Belgrano, pp. 179 y 180. 
sino enfocadas desde un contexto de aplicación y particular (con relación a su dominio de casos) para la formación del colectivo proceso; es decir, se afecta la validez de la relación jurídica procesal particular de que se trate. En suma, si los entes son distintos: el colectivo y de sus miembros, y bajo la prohibición de la falacia de la división (no traspasar las características del todo a sus miembros ${ }^{22}$ ), entonces las propiedades o características del colectivo procesal no se traspasan necesariamente a cada uno de sus miembros (actos y resoluciones singulares); cada uno tiene su propio régimen, distinguiéndose los presupuestos del proceso del de los actos y resoluciones singulares. De lo que se concluye, entonces, que lo invalidado es el proceso y no necesariamente las resoluciones singulares ni inadmisibles sus actos singulares que lo componen (los que efectivamente sí han sucedido).

(a) Ello explica por qué la resolución singular que declara inválido el proceso, puede ser ella misma válida.

(b) Explica también que, dado que el proceso como colectivo es el inválido, deba detenerse, precisamente como expresión y consecuencia propia de dicha invalidez de la clase presente, al imposibilitar el curso del ejercicio de la efectiva tutela jurisdiccional ${ }^{23}$ (recuérdese que el proceso se entiende como una sucesión de actos y resoluciones singulares que apuntan a la resolución final con autoridad de cosa juzgada).

Ahora bien, de que no necesariamente traspasen las propiedades entre colectivo y su miembros, no se sigue que contingentemente sí puedan coincidir algunas entre ellos ${ }^{24}$. En tal sentido, debe revisarse qué miembros -actos y resoluciones- del colectivo proceso, pueden verse afectados por el "hecho vicioso" que merece la calificación de presupuesto procesal, pero que, además, pueda compartir el carácter de requisito de los actos y resoluciones singulares, para su admisibilidad o validez; p. ej., que las resoluciones judiciales sean dictadas por un juez, o que un acto de parte sea de alguien existente. Cada uno de aquellos estará sometido al régimen propio de los actos y resoluciones singulares. En otras palabras, si se considera determinado hecho para evaluar un acto o resolución, no es porque se aplique el régimen de los presupuestos procesales, sino por ser requisito del acto o resolución particular de que se trate. En tal sentido, si se quiere contraargumentar señalando que todos los actos y resoluciones procesales

22 Ejemplo clásico de esta falacia es que si el Congreso es una institución desprestigiada, de ahí se seguiría (inválidamente) que todos los congresistas que lo componen estén desprestigiados. Salmon (1965) 59; Copi (1994) 111-113; Gómez / Buera (1984) 180-181.

23 Rosenberg (1955) 50 y Goldschmidt (1936) 193, señalan que la sentencia que detiene el proceso y libera al sujeto pasivo es una absolución de la instancia; es decir, es susceptible de atribuírsele suma preclusión, pero no autoridad de cosa juzgada.

24 Por ejemplo, de que el Congreso sea una institución desprestigiada, no se sigue que no puedan haber congresistas desprestigiados. 
tienen como requisito los mismos presupuestos procesales, por lo tanto, los presupuestos procesales también lo son de los actos, entonces se incurriría en la falacia de identitatio efectum identitatio causa. Es decir, se estaría justificando mediante la apelación a las mismas consecuencias que existiría el mismo título.

Si bien todos los presupuestos procesales afectan la validez del proceso como colectivo, la intensidad con que lo afectan no es de igual modo. Si la falta de presupuesto es un vicio, entonces pueden clasificarse los vicios de acuerdo a qué consecuencia le atribuye el sistema del Derecho Procesal. i) Existe una invalidez ipso iure del proceso frente a determinadas faltas de presupuestos, ii) mientras que otras deben ser legalmente constituidas por resolución. Asimismo, i) hay algunas que son insaneables ni aun por la suma preclusión, ii) mientras que otros sí lo son. Las primeras producen una invalidez radical, y si bien algunas establecen ciertas vías para ser subsanadas a efectos de que el proceso continúe (v. gr., la falta de capacidad de ser parte, en ciertos $\operatorname{casos}^{25}$ ), mientras no sean subsanadas pueden afectar hasta la autoridad de la cosa juzgada misma. La razón es que afectan de manera grave la constitución del proceso. Debe dejarse constancia que en este mismo primer grupo algunos vicios no podrán ser subsanadas (v. gr., la falta de jurisdicción). Usualmente a este grupo se le llama con el pésimo nombre de "existencia". Por su parte, a los del segundo grupo, dada su menor trascendencia sobre el proceso, tiene un régimen más suave para tratar los vicios; a estos usualmente se les llama de "validez". Sin embargo, según ya se dijo, ambos son de invalidez del proceso; solo que una es radical y la otra no. Los presupuestos procesales por excelencia son los primeros.

En tal sentido, en el caso 'Novoa Chevesich y otro con SII la Corte de Apelaciones de Santiago, de la pluma del juez Dahm, aplicó la construcción de los presupuestos procesales de invalidez radical. Así, decretó que "son requisitos para que un juicio tenga existencia jurídica, la existencia de un juez que ejerza jurisdicción, la de las partes... La falta de concurrencia de alguno de ellos acarrea la inexistencia del juicio", y agrega en contraposición que "son requisitos de validez del juicio, el que se litigue ante tribunal competente, que las partes sean capaces y que se cumplan con determinadas formalidades que la ley señala" (consid. 30); distinción que es supuesta en el caso 'Quezada Arias con Farías Lauri'26. De tal manera

25 Por ejemplo, puede subsanarse en la medida que el proceso no sea personalísimo; como en los divorcios.

26 La Corte de Apelaciones de Valparaíso en el caso sub lite, recurre a la categoría de existencia del proceso: "Al respecto la doctrina está conteste que el conflicto jurídico objeto del proceso debe producirse entre partes y que la ausencia de cualquiera de los presupuesto procesales de existencia -un órgano jurisdiccional, un conflicto de relevancia jurídica y la existencia física o legal de las partes-, trae aparejada la inexistencia del proceso" (consid. $7^{\circ}$ ). 
que, dependiendo del tipo de presupuesto se puede llegar a afectar incluso la propia suma preclusión (o mal llamada autoridad de la cosa juzgada formal) como señala la sentencia que se comenta.

\section{(2.3) OBSERVACIÓN CRÍTICA}

Si la posición expuesta es acertada, entonces no es correcta la observación de la Corte de Apelaciones de Valparaíso cometiendo precisamente la falacia de la división, cuando señala, a secas, que la falta de presupuestos procesales "trae aparejada la inexistencia del proceso, con todas las consecuencias que ello trae consigo, en especial, que todas las actuaciones realizadas en el proceso, asi como la sentencia misma, carezcan de valor" (consid. $7^{\circ}$ ). La primera parte del argumento es correcta, pero es en el paso a la segunda en donde ocurre el vicio argumentativo.

\section{3) Procesos PERSONALÍSIMOS}

Pero el problema del proceso sub lite no queda allí. En verdad, antes de enfrentarse a las graves consecuencias de la falta de presupuestos procesales, que pesan sobre el proceso como un todo, la ley en diversas circunstancias presenta ciertas herramientas para evitarlas (sin perjuicio de si puede afectarse a determinados actos del proceso) ${ }^{27}$. Uno de dichos instrumentos lo constituye el mecanismo de la sucesión de parte, que contempla, p. ej., el art. 5 del CPC. Mediante dicho mecanismo se reemplaza una persona que ocupa una determinada posición normativa en el proceso, por otra u otras que quedan dispuestas en la misma posición normativa procesal del antecesor.

Lo interesante del caso en comento es que la Corte logra darse cuenta de que el problema entre manos contiene elementos implícitos del Derecho: un presupuesto del contenido normativo del art. 5 CPC, y deslinda correctamente dicho presupuesto de operatividad de la norma de aquello que no lo sea. Esto se concreta en que logra separar aguas conceptuales entre tipos de procesos según la calificación de los sujetos intervinientes como partes. Así se ve la distinción entre procesos personalísimos frente a aquellos que tienen sujetos o partes reemplazables. En los primeros, la relación normativo-procesal se plantea entre determinadas personas exclusivamente, de tal manera que al faltar una persona no puede reemplazarse en su posición por otra; dándose el supuesto de la carencia personal, se extingue la parte. Esto se basa, en último término, en el carácter ho-

27 Mediante ciertas herramientas jurídicas podría eventualmente salvarse el proceso como un todo, pero no así salvarse singulares actos del proceso. 
lista ${ }^{28}$ del Derecho de la Codificación que produce interconexiones de variopinta naturaleza entre diversas áreas (por lo que no tiene causa en una transformación civilista del proceso). En la clase de casos analizada, la interrelación del Derecho procesal se da con cuestiones de Derecho material, pues se mira a la relación jurídica de fondo; en otros términos, se fundamenta en ciertas decisiones de política legislativa respecto a la comprensión de determinados aspectos de la vida jurídica (extraprocesal) de los ciudadanos -según veremos-, que se concreta en una determinada estructura de la relación de fondo. Un claro ejemplo de ello es el Derecho procesal penal, en que la responsabilidad penal es personalísima y al morir el acusado, su situación procesal penal no se traspasa a sus sucesores.

De tal guisa, uno de los aspectos importantes de la sentencia es que logra dar cuenta del carácter personalísimo del proceso, evitando que opere la sucesión procesal del art. 5 CPC (y que, por supuesto, no debía operar). Ello porque la relación material del matrimonio, en tanto régimen personal y no patrimonial, se entabla exclusivamente entre ciertas y determinadas personas: los dos cónyuges. Nadie más puede reemplazarlos. Así puede verse que de acuerdo al art. 56 LMC, la "acción de divorcio pertenece exclusivamente a los cónyuges", lo que se complementa con lo normado por el art. $42 \mathrm{n}^{\circ} 1 \mathrm{LMC}$, que determina que la muerte pone fin al matrimonio, cercenándose cualquier posibilidad de reemplazo ${ }^{29}$. El carácter personalísimo de una relación jurídica procesal, además, puede clasificarse en unilateral o bilateral, según se afecte a una o ambas partes. El tipo de caso en comento es claro: el carácter es "bilateral", porque afecta a ambas partes del proceso; a diferencia de la interdicción por demencia que puede estimarse como "unilateral", es decir, que afecta a una sola parte, p. ej., el demandado por interdicción. Este deslinde constituye un fundamento del fallo, al sostener la Corte de Valparaíso: “... siendo un elemento esencial en el proceso la existencia natural de las partes, sobre todo que se trata de una materia que afecta directamente la situación personal de ellos y porque en la especie se encuentran en juego derechos personalisimos" (consid. 6o ${ }^{30}$. Observemos que la sentencia logra conectar

28 Esta característica dice relación con que todas las partes del Derecho están potencialmente conectados de manera sistemática.

29 Para efectos de evitar ciertas ambigüedades, debemos precisar que, el matrimonio puede ser visto desde dos perspectivas, como el orden jurídico matrimonial singular y el acto de constitución de dicha relación. En tanto acto o acuerdo no es personalísimo, pero, en tanto orden jurídico constituido, la configuración que tiene es, en general, de carácter personalísima. Recuérdese que, además, tiene el rasgo de ser intuito persona.

30 La constatación es relativamente similar a la que hace la fiscal judicial Nash al señalar que: "Desde un prisma sustantivo, lo primero que hay que considerar es que el matrimonio, atendido su especial carácter, es un contrato intuito personae, bilateral, en el que la consideración de la persona del otro contrayente es el motivo principal de su celebración" (pár. $4^{\circ}$ ). Sin embargo, el informe argumenta que al ser intuito persona el matrimonio, el proceso terminó de manera previa con la muerte -de pleno Derecho-, por lo que (sumado al objeto 
correctamente la cuestión de fondo personal de las personas involucradas, en relación con el carácter personalísimo del proceso, plasmando así una consecuencia del carácter instrumental del Derecho Procesal ${ }^{31}$. De esta manera, mediante dicha estimación, la Corte logró remover una condición positiva -la posibilidad de sucesión procesal- que obstruía la posibilidad de dar lugar al efecto negativo de los presupuestos procesales ${ }^{32}$.

\section{4) DeCAimiento 33}

Dentro del problema de la causa sub lite está que, además, si se pretende anular o privar de validez al proceso, existe una regla bastante clara sobre ello: los vicios deben ser iniciales y no sobrevenidos para que opere la nulidad.

La Corte de Valparaíso tiene conciencia de la situación del decaimiento, al señalar "por cuanto en la especie al haber muerto uno de los contrayentes durante la substanciación del proceso, ha desaparecido uno de los presupuestos de existencia del proceso...". Sin embargo, su fundamentación es un tanto tangencial, recurriendo a un argumento con forma consecuencialista: "en el presente caso se trata de una circunstancia que evidentemente produce la nulidad del procedimiento, pues de seguirse adelante con el proceso, los efectos de las resoluciones judiciales podrian afectar eventualmente a una parte sin existencia legal, lo que es contrario a cualquier acto jurídico procesal" (consid. 80), y agrega, más adelante, que la existencia natural de la persona constituye una carencia "de un requisito esencial" (consid. 9\%).

procesal de poner fin al matrimonio) el proceso de divorcio no tendría sentido (pár. $7^{\circ}$ ). Establecido ello, solo recién relaciona el tema con la cosa juzgada aparente y con la inexistencia del proceso (pár. $8^{\circ}$ ), para enfrentar el argumento del desasimiento del tribunal (pár. $10^{\circ}$ ), que al parecer parecía ya superado en la argumentación, en tanto la formal precede a la de fondo.

De todas formas, en el pár. $11^{\circ}$ relaciona los temas al señalar: "Así el fallecimiento del actor... implicó en este caso que uno de los elementos de existencia del proceso de divorcio desapareciera, poniéndose término al mismo por la ausencia de uno de los presupuestos procesales constituido por la existencia del actor, parte que sustenta la pretensión de divorcio, acción personalísima y, por ende, intransmisible".

31 Es curioso que en esta materia de los presupuestos procesales, que fue el origen de la autonomía del Derecho Procesal, la sentencia comentada sobre este tema, muestre claramente la conexión e influencia de ciertas relaciones de fondo, precisamente, sobre el desenvolvimiento de los presupuestos procesales.

32 Del argumento desarrollado por los jueces porteńos, se muestra con claridad, además, que el art. 529 COT no está dentro de las normas directamente relacionadas con la sucesión procesal, o en su primera línea, sino que precisamente está desplazado por consideraciones teóricas y normativas sobre los presupuestos procesales, y el tipo de proceso de que se trate.

33 El considerando 22 del caso 'Sociedad Sánchez y Sánchez Limitada con SII, refiere expresamente al "decaimiento" aunque para los efectos del proceso, que sin embargo derivan de un decaimiento de un presupuesto procesal. 
Algunos autores también apuntan a ciertos argumentos consecuencialistas. Montero Aroca, señala que con la presentación formal de la acción "se produce la perpetuatio legitimationis, en virtud de la cual quienes estaban legitimados en el momento de la litispendencia mantienen esa legitimación, sin perjuicio de los cambios que puedan producirse en el tiempo de duración del proceso", pero agrega una advertencia: "ello no puede llevarse a sus últimas consecuencias en contra de la misma realidad, y que no solo se admiten cambios de parte derivados de hechos naturales (como la muerte de uno de los litigantes)" 34 .

En verdad, la sentencia tiene un buen punto, pero debió expresarse derechamente y no como una razón con forma consecuencial. Dada la trascendencia de los presupuestos procesales, estos no deben considerarse como exigencias previas de corte temporal. Se trata más bien de exigencias lógicamente previas en la construcción de la idea de proceso. Ahora bien, dado que el proceso es un todo o colectivo, los presupuestos deben mantenerse durante todo el colectivo, hasta el arribo de la aplicación de la tutela jurisdiccional. Por lo expuesto, su decaimiento o ausencia ex post, igualmente importa la falta de un elemento lógicamente previo a todo proceso $y$, en particular, al proceso singular de que se trate.

\section{5) FORMA DE HACER VALER LA AUSENCIA}

En este tema podemos ver una relativa línea continua entre el fallo en comento y el caso 'Novoa Chevesich con SIT. Ya en el informe de Nash, citando a Romero, se hace referencia al fallo de la Corte de Santiago en orden a "que '....allí se constató la existencia de una cosa juzgada aparente y se admitió la posibilidad de ser removida de oficio, en virtud de las facultades del artículo 84 del Código de Procedimiento Civil. Según la doctrina de la Corte, debe declararse de oficio la cosa juzgada aparente, cuando falta alguno de los requisitos que acarrea la inexistencia del juicio...' (Alejandro Romero Seguel...)" (pár 80). En realidad el fallo de la Corte de Santiago es bastante escueto y procede por defecto: determina que existe un vicio de existencia del proceso (en el consid. $3^{\circ}$ en relación con el $8^{\circ}$ ), y luego afirma que, dado que el vicio no es convalidable (consid. $9^{\circ}$ ), no es factible aplicar el art. $83 \mathrm{CPC}$ que sí tiene plazo de saneamiento (consid. $10^{\circ}$ ), por lo que para controlar tan grave vicio y considerando que no debe interpretarse de manera muy rígida los requisitos legales, en contra de la función de administrar

34 Montero Aroca, J. et al. (2001). Derecho Jurisdiccional, t. II, 10a ed., Valencia: Tiranch lo Blanc, p. 195. Entre nosotros, Carocca señala que la perpetuatio legitimationis constituye una ficción; en consecuencia, no puede impedir que opere la sucesión de algunas de las partes. Carocca, A. (2003). Manual de Derecho Procesal, t. II, Santiago: LexisNexis, p. 90. 
justicia (consids. $17^{\circ}$ y $18^{\circ}$ ), por descarte queda el art. 84 CPC (en lo resolutivo del fallo) ${ }^{35}$.

La Corte de Apelaciones de Valparaíso basada en la idea de inexistencia del proceso sostiene que hay cosa juzgada aparente (o apariencia de suma preclusión), por lo que "aun cuando se hubiera inscrito la referida sentencia de divorcio, igualmente no podría prevalecer ella a la muerte... pues en ese caso estaríamos en presencia de un proceso aparente" (consid. $\left.6^{\circ}\right)$. Y reconoció que "sobre el particular, nuestra legislación no contempla en forma expresa y específica la manera de reclamar la inexistencia”, y liga su sentencia con la labor de la judicatura al señalar que "pero ha sido la jurisprudencia que ha señalado que ella puede alegarse por vía de excepción perentoria, cuando corresponda procesalmente, o bien por vía de nulidad, como se ha hecho en el presente caso, esto es, cuando se hace a petición de parte" (consid. $8^{\circ}$ ).

Finalmente, como tercera vía, la Corte dispuso que "aún más, tratándose de requisitos de existencia, también el Tribunal puede, en base a las facultades que le son conferidas por el artículo 84 inciso final del Código de Procedimiento Civil, declarar la nulidad de oficio. En efecto, en el presente caso se trata de una circunstancia que evidentemente produce la nulidad del procedimiento" (consid. 80). El inciso final del art. 84 CPC dispone dos potestades para el juez:

$1^{\circ}$ faculta al juez para corregir de oficio los errores de tramitación;

$2^{\circ}$ faculta a tomar las medidas tendientes a evitar la nulidad de los actos del procedimiento.

Es el primer supuesto en que se basa la Corte para efectos de permitir la corrección de los vicios del proceso.

Pero aquí surge una cuestión no menor: el tipo de consecuencia o sanción. Una cosa es que la Corte alegue la consecuencia de la inexistencia y otra es que argumente y aplique la sanción de la nulidad procesal. De acuerdo a las consideraciones teóricas regulares que manejaba la Corte, se trata de consecuencias disímiles, una supone que no hubo proceso y la otra supone que sí lo hubo, pero que se invalida; además, del requisito del "perjuicio" aplicable a la segunda pero no a la primera. La Corte no lo resuelve y simplemente omite como si fuesen lo mismo, incurriendo

35 En realidad, aquí se produce un desvío argumentativo del fallo. Comienza razonando sobre presupuestos procesales en relación con la apariencia de autoridad cosa juzgada y remata con el problema de la autoridad fraudulenta. En verdad, lo fraudulento también remata en la ausencia de presupuestos procesales, pero de manera contingente. Lo que muestra que al desviarse cambia la dirección del argumento no dando necesariamente el mismo resultado. Vid. la crítica a ligar lo fraudulento de la autoridad de cosa juzgada con la nulidad procesal del art. 84 CPC en Romero (2001) 787-788. 
en una falacia (en tal sentido, y por lo visto, tampoco da lo mismo haber decretado la inadmisibilidad del proceso). Más consistente habría sido considerar una invalidez ipso iure del proceso, insanable por el tipo del mismo.

Sin embargo, queda otro problema: el inciso final del artículo 84 no permite salvar las actuaciones realizadas fuera de los plazos legales, tales como el del art. $83 \mathrm{CPC}$, para denunciar los vicios. No estamos en presencia aquí del problema del art. 80 del CPC, el cual, como concreta el art. 234 inc. 4 CPC, habilita la petición de nulidad procesal incluso más allá de la sentencia definitiva y la suma preclusión. Entonces, ¿cómo explicar la operatividad de la figura de la nulidad?

Aquí se va a producir algo complejo, porque con la sola normativa explícita de la nulidad no alcanza a explicarse lo ocurrido, ni, por otra parte, logra darse una buena salida a la necesidad, en principio razonable, de remediar las consecuencias negativas de la falta de presupuesto procesal. La solución debe venir por los elementos implícitos del Derecho (engarzados con los explícitos), reconstruidos por la teoría procesal.

En tal sentido, debe mirarse la norma del art. 84 CPC no de manera aislada, sino holista, en un todo: en el conjunto de la institución de la $n u-$ lidad procesal. Esto implica que debe integrarse junto a todo el articulado referido a dicho tema, así como a toda la reconstrucción jurídica de la normativa implícita de la mentada nulidad. De acuerdo a la moderna tendencia procesal, este instituto tiene un rasgo predominantemente pragmático, en que se lo concibe más bien como un remedio a ciertas cuestiones graves, en vez de la natural o normal consecuencia de la irregularidad de un acto. El ángulo o enfoque desde que se parte es opuesto desde la teoría de las normas, y nos presenta una construcción diversa según dicho punto de partida. Ello tiene la virtud de explicar el que a no toda irregularidad de una resolución sea atribuida o adjudicada la nulidad (p.ej., en la convalidación, la renuncia, la mera irregularidad), por un extremo, o que no toda incidencia de nulidad se extinga en los cipos de cualquier preclusión (p. ej., art. 234 inc. 4 CPC), por otro.

En tal sentido, la nulidad procesal puede ser enfocada, tal y como lo hace la sentencia del caso 'Quezada Arias con Farias Lauri', es decir, como un remedio para la grave cuestión de afectarse los presupuestos procesales. Por lo tanto, la nulidad, como institución, en parte también está al servicio de este grave problema. Esto implica que como un todo, todas sus regulaciones implícitas y explícitas deben ser referidas, en cuanto sean pertinentes a dicha solución. Ahora bien, si consideramos al art. 234 inc. 4 CPC como un ejemplo de solución a los problemas más gravísimos del ordenamiento adjetivo que acoge la nulidad procesal, podemos comprender que la nulidad, como instituto, puede extender y extiende sus raíces más allá de la suma preclusión. En tal sentido, este ejemplo corrobora la tesis de que la nulidad procesal también puede ser vista como un remedio 
para los casos más graves y gravísimos de transgresión del orden procedimental (valorativamente considerado), y que en estos últimos casos, puede extenderse más allá de la sentencia definitiva, teniendo en ese sentido un alcance variable.

$\mathrm{Si}$ aquello es así, entonces la nulidad procesal del art. $83 \mathrm{CPC}$ al abarcar también los hechos más gravísimos del proceso, como son los presupuestos procesales, ha de obviar el problema de ciertos casos de preclusión. Esto implica que las normas de preclusión para la petición de nulidad y su efecto reflejo cercenador de los poderes anuladores del juez ${ }^{36}$, que contemplan tanto el art. 83 como el $84 \mathrm{CPC}$, están dispuestas para los casos normales de irregularidad grave, mas no están configuradas ni están dirigidas a los casos más gravísimos de antijuridicidad procesal. Es mediante el análisis teórico que podemos determinar en el caso singular la gravedad del vicio, en nuestro caso de la ausencia de los presupuestos procesales, para efectos de caer en los casos de excepción del art. 84 inc. 3 CPC al plazo del art. 83 CPC, cuando se afecte a la ritualidad del proceso, que por supuesto no se agota en los presupuestos procesales. Fijada así la extensión de la preclusión, tenemos que, en consecuencia, aquellos casos más gravísimos constituirán una excepción al régimen normal preclusivo, debiendo determinarse según cada clase de caso, hasta dónde llegan los poderes anulatorios del juez, que, por supuesto, pueden extenderse potencialmente, más allá de la preclusión o incluso de la suma preclusión.

La gravedad pragmática la determina la sentencia al aludir al criterio de existencia: "Que, aún más, tratándose de requisitos de existencia, también el Tribunal puede, en base a las facultades que le son conferidas por el artículo 84 inciso final... declarar la nulidad de oficio" (consid. 8). Y las consecuencias por supuesto que el tribunal las presenta como elemento de juicio: "en el presente caso se trata de una circunstancia que evidentemente produce la nulidad del procedimiento, pues de seguirse adelante con el proceso, los efectos de las resoluciones judiciales podrían afectar eventualmente a una parte sin existencia legal" (consid. 8). De tal manera que dada la gravedad del presupuesto procesal involucrado, sobre la existencia del proceso, se hace admisible el incidente "pues así debe ser declarado [como nulo]" (consid. 9); (el giro pragmático de la nulidad procesal).

La solución anterior nos conduce lógicamente a un último problema. Si se argumentó con la nulidad procesal, debió aplicarse el régimen de esta, es decir, exigir el perjuicio procesal. Dicho daño es uno de carácter técnico y específico: una afectación al derecho de defensa, cuestión que no se da en el caso. La parte solo alegó un perjuicio extraprocesal, el interés pecuniario en la herencia del actor y marido. Nuevamente surge aquí el problema del régimen del presupuesto procesal. Si se invocase solo

36 Sobre los efectos reflejos de la preclusión Gandulfo (2009) 137. 
la inadmisibilidad, no habría necesidad de perjuicio técnico. Lo mismo ocurre con la inexistencia, basta la constatación. Sin embargo, la nulidad sí requiere de un desarrollo técnico especial que la sentencia en comento omitió. Y en este punto se da un problema metodológico: o bien, se opta por otra sanción con todas sus consecuencias teóricas, o bien, se modifica la teoría de la nulidad para cierta subclase de casos.

\section{7) LECCIONES}

Muchos podrían haber señalado que el problema del caso sub lite podría haber sido resuelto de cualquier forma, en la medida que se obtuviese una consecuencia satisfactoria para la intuición moral sobre quién debió ser favorecido. Sin embargo, tal tipo de antimetodología nos llevaría rápidamente por un muy oscuro camino. En efecto, si cualquiera fuese la solución válida en pos de un fin, entonces adquiriría enorme relevancia la sabiduría del juez para determinar y distinguir quién es el moralmente bueno de quién no en el caso, a efectos de saber cuál es el fin que se debe buscar y luego sería la mera sabiduría del juez la que deba "adecuar" las reglas al ciudadano favorecido por la buena apreciación del juez de sus méritos morales en relación con el caso.

Por el contrario, la solución de la Corte porteña se enmarca dentro de lo más noble de la tradición jurídica de la Codificación: la búsqueda de soluciones repetibles para un caso singular, mediante echar mano al recurso del acervo teórico disponible. Su gran mérito estriba en el esfuerzo intelectual de buscar la solución teórica más razonable al caso. Una teoría jurídica no solo tiene un fin cognoscitivo sino también pragmático. Por lo mismo, una teoría, a diferencia de soluciones ad hoc, permite un mejor control de la misma, para evitar una administración de justicia de meras apariencias de justicia. En tal sentido, la teoría permite una mejor observación del "fenómeno jurídico", controlando las consecuencias prácticas y permitiendo a los jueces tener en rienda relativamente firme la extensión de los brazos de la misma. Es por ello que la teoría de los presupuestos procesales, si bien no es del todo bien invocada, es relativamente bien utilizada en lo nuclear, para obtener una solución razonable, a la vez que la sentencia permite templar a buen fuego los límites de esta compleja teoría de los presupuestos (sin perjuicio de las insuficiencias teóricas e inconsistencias de la explicación invocada).

\section{BIBLIOGRAFÍA}

- Briseño Sierra, H. (1966). "Excepciones Procesales", en Revista de la Facultad de Derecho de México, No 63-64. 
Presupuestos procesales y su decaimiento en los juicios personalísimos. La capacidad procesal...

- Carocca, A. (2003). Manual de Derecho Procesal, t. II, Santiago: LexisNexis.

- Copi, I. (1994). Introducción a la Lógica, Buenos Aires: EUDEBA.

- Couture, E. (1958). Fundamentos de Derecho Procesal Civil, $3^{a}$ edic., Buenos Aires: Depalma.

- Fairén, V. (1992). Teoría General del Derecho Procesal, México: UNAM.

- Gandulfo, E. (2009). "Sobre Preclusiones Procesales en el Derecho Chileno en Tiempo de Reformas", en Ius et Praxis, Vol. 15, No 1.

- Goldschmidt, J. (1936). Derecho Procesal Civil, Barcelona: Labor.

- Gómez, A. I Buera, O.M. (1984). Análisis del Lenguaje Jurídico, Buenos Aires: Belgrano.

- Montero Aroca, J. et al. (2001). Derecho Jurisdiccional, t. II, 10a ed., Valencia: Tiranch lo Blanc.

- Pastor, D. (2001). Acerca de Presupuestos e Impedimentos Procesales y sus Tendencias Actuales, en Nuevas Formulaciones en las Ciencias Penales, Buenos Aires: Lernes.

- Pereira, H. (2004). La Cosa Juzgada en el Proceso Civil, Santiago: LexisNexis.

- Pérez Ragone, A. (2010). “¿Presupuestos Procesales? Admisibilidad y Fundabilidad en la Dogmática Procesal Civil Alemana: Revisión Contemporánea”, en Teoria do Processo, Vol. 2, pp. 21 a 44.

- Romero, A. (2001). "El Control de Oficio de los Presupuestos Procesales y la Cosa Juzgada Aparente. La Capacidad Procesal”, en RCHD, Vol. 28.

- Romero, A. (2004). "La Falta de Jurisdicción y su Denuncia en el Proceso: las Excepciones Procesales y Materiales”, en RCHD, Vol. 31.

- Romero, A. (2006). Curso de Derecho Procesal, t. I, Santiago: Editorial Jurídica de Chile.

- Rosenberg, L. (1955). Tratado de Derecho Procesal Civil, t. II, Buenos Aires: EJEA.

- Salmon, W. (1965). Lógica, México: UTEHA.

- Schmidt, Eb. (1957). Los Fundamentos Teóricos y Constitucionales del Derecho Procesal Penal, Buenos Aires: Editorial Bibliográfica Argentina.

- Von Bülow, O. (1868). La Teoría de las Excepciones Procesales y los Presupuestos Procesales, EJEA, trad. M. Rosas, B. Aires, pp. 4 y ss. Disponible en http://forodelderecho.blogcindario. com/2011/05/01622-la-teoria-de-las-excepciones-y-lospresupuestos-procesales-oskar-von-bulow.html 